\title{
Beyond social chit chat? Analysing the social practice of a mobile messaging service on a higher education teacher development course
}

Clare TyreriD

Correspondence: claretyrer100@ gmail.com

Faculty of Arts and Social Sciences, Lancaster University, Bailrigg, Lancaster LA1 4YT, England, UK

\begin{abstract}
Mobile technology has become for many an essential aspect of everyday life. It has transformed how people interact and is widely adopted by social networks to facilitate communication, support engagement and build collaboration. With reference to Shove et al., (The dynamics of social practice: Everyday life and how it changes, 2012) three element social practice model and Wenger (Communities of Practice: learning, meaning and identity, 1998) community of practice framework, this "insider" research study analyses the norms, behaviours and attitudes of users of a mobile messaging service over a two-year higher education teacher training programme. It also examines the socio-technical interaction between the trainee teachers and the relationship between the mobile messaging application and other communicative practices.. Overall, the findings from this research study suggest that although the concept of a community of practice is problematic, the WhatsApp practice positively shaped the experiences of the trainee teachers on their programme.
\end{abstract}

Keywords: Mobile messaging service, Social practice, Community of practice, Social networks, Interaction

\section{Introduction}

Mobile communication technology in the twenty-first century has become for many an essential aspect of everyday life, transforming social relationships and interactions (Ellison \& Boyd, 2013; Katz \& Aakhus, 2002). It has enabled users to form social networks which transcend boundaries of space and time, and which "provide sociability, support, information, a sense of belonging and social identity" (Wellman, 2001, p. 228). Participants can interact on the move) and from moment to moment). Although not physically present, there is still a need for proximity (Boden \& Molotch, 1994; Urry, 2002) and building social capital, defined by Lin (2001, p. 19) as "investment in social relations with expected returns in the marketplace."

The context of this study is a part-time two-year higher education teacher training programme. During the course, trainee teachers are exposed to and expected to assimilate a vast amount of information concerning pedagogy and professional practice They will also face challenges on their teaching placements. By having access to a

(c) The Author(s). 2019 Open Access This article is distributed under the terms of the Creative Commons Attribution 4.0 International License (http://creativecommons.org/licenses/by/4.0/), which permits unrestricted use, distribution, and reproduction in any medium, provided you give appropriate credit to the original author(s) and the source, provide a link to the Creative Commons license, and indicate if changes were made. 
supportive group, they can share information and resources, alleviate some of their fears and boost their self-esteem.

One significant development in the formation of social networks has been the use of mobile messaging applications for Smartphones, such as the market leader WhatsApp. Created in 2009 by Koum and Acton, former employees of Yahoo, WhatsApp was originally conceived as a cheaper alternative to SMS (Short Message Service), but it has developed from a simple communication tool into a cross-platform instant messaging service, enabling users to send longer texts and exchange images, videos, messages and sound files via their internet connection. It was acquired by Facebook in 2014 and, according to its website, is currently used by more than one billion people worldwide (WhatsApp, 2018). The reasons for its appeal lie in its simplicity, relative inconspicuousness, convenience and low cost. It may also be a symbol of conformity or a desire for social acceptance and communality. In 2016, WhatsApp dropped its subscription charge and it is now free to download and send messages (Independent, 2016). It has gained more popularity in informal educational settings as a collaborative virtual learning space, giving learners the freedom and flexibility to interact away from the four walls of the institution).

The aim of this study is to analyse the emerging practice of WhatsApp on the teacher development programme. The trainee teachers voluntarily set up a WhatsApp group as they wanted an uninhabited, collaborative space where they could explore mutual areas of relevance in relation to the course.

The following three research questions were designed:

1. In what ways is WhatsApp used by the participants on the programme?

2. How are socio-technical relations maintained in the WhatsApp community of practice?

3. What is the relationship between WhatsApp and other communicative practices?

\section{Theoretical framework}

In this section, reference is made to two theories. Firstly, to try to make sense of the routinised performance of WhatsApp on the teacher education course, it was necessary to turn to practice theory to explore the specific "doings" and "sayings" of the practice. Most research into mobile technology to date has focused on its different affordances and how these facilitate learning (Adami \& Kress, 2010; Churchill \& Hedberg, 2008; Orr, 2010). However, learning does not occur in isolation and it is useful to move away from exploring how technology can aid the delivery of content) to how it is adopted and integrated into informal educational settings with other social practices (Merchant, 2012).

The idea that context and interaction shape knowledge and understanding (Corradi, Gheradi, \& Verzelloni, 2010) links to Wenger's (1998) view that learning occurs through participation in a community of practice. Drawing specifically on his community of practice framework, it was valuable to analyse how the practice itself affects sociality.

\section{Practice theory}

Schatzki (1996, p. 87) defines a practice as "a temporally =, open-ended set of doings and sayings linked by practical understandings, rules, teleo-affective structures and general 
understandings." To have a better understanding of a practice, we need to closely examine the specific activities people do, the different meanings they associate with it, and the interconnected material elements. Practices are perceived as "routinized behaviours" (Reckwitz, 2002a) such as washing-up, having a shower and sending an email. They have distinct histories, and these help us to understand how likely they are to be adopted or sustained in different contexts.

A social practice-based approach is not a unified theory (Schatzki, 2001) but more of a set of observations that can generate theories. It has been a source of interest for researchers in various disciplines, primarily those concerned with consumption and sustainability studies (Evans, McMeekin, Warde, \& Southerton, 2012; Gram-Hanssen, 2009; Halkier \& Jensen, 2011; Hargreaves, 2011; Warde, 2005), food and health (Cheng, Olsen, Southerton, \& Warde, 2007; Will \& Weiner, 2014; Maller, 2015; Blue, Shove, Caromona, \& Kelly, 2016;) and mobility and transport (Harries \& Rettie, 2017; Spotswood, Chatterton, Tapp, \& Williams, 2015; Watson, 2012). A feature common to all practice theories is taking ordinary human actions as the unit of analysis rather than a focus on individuals, systems or structures. With a practice approach, the emphasis is on doings and sayings rather than what people think. This does not mean that individuals have no control over how a practice is performed, but foregrounding ordinary actions shifts the focus of study and intervention to the different elements which constitute practices: materials, competences and meanings. These interconnected components seen as "practice as entities" (Schatzki, 1996; Shove, Pantzar, \& Watson, 2012; Warde, 2005) have a universal meaning but vary and develop in different contexts as people "adapt, improvise and experiment" (Warde, 2005, p. 41); they are enacted and carried by individuals through their performance. For example, if we consider texting to be a practice, it is only through individuals' engagement with it and the regularity and repetition of use that the practice will survive.

For this study, Shove et al.'s (2012) three element model, comprising materials, competences and meaning, was used to explore the practice of WhatsApp. Spotswood et al. (2015) argue that this is the most valuable way of applying social practice theory to exploring behaviour change as it offers a simpler approach. The researcher can gain a more holistic and meaningful view of participants' norms and behaviours, examine the dynamic interplay between the different components and how they impact on other communicative practices. The conceptual elements which constitute the social practice of WhatsApp are summarised below.

\section{Materials}

Material elements are notably absent in Schatzkis practice theory (1996). Objects are regarded as "symbolic markers" (Reckwitz, 2002b, p. 211), linked to their contexts of use: "places are anchored in objects which are combined into settings" (Schatzki, 1996, p. 189). However, the importance of artefacts in social practices should not be ignored. As Reckwitz (2002b) argues, most practices involve interaction with non-human "things". Although technological artefacts shape social interaction, they only have an impact if they are connected to practical knowledge and understanding (Shove et al, 2012), as summarised by Reckwitz (2002b, p. 213):

social order and reproduction can be adequately understood only when we realise their double localization: as understanding incorporated in human bodies and an understanding materialized in artefacts. 
Central to the practice of WhatsApp is access to its appropriate material elements: a Smartphone, mobile network and phone charger. "Softer influences" such as making time to integrate the practice into everyday life (Darnton \& Evans, 2013, p. 5) are also present. Mobile phones have a history and, given that more than five billion people are estimated to own one by 2025 (Miller, 2012), it seems very unlikely they will not have a future. WhatsApp co-exists with other social practices such as using the mobile phone to make calls or search for information on the internet as Lehtonen (2003, p. 371) posits:

The higher the number of attachments and practices that are potentially connected with a technology and the better it fulfils the promise associated with it, the more likely a technology is to be seen as something "necessary".

Clearly, if mobile phones had only the one function of being able to make wireless calls, they would not have transformed society to the extent they have done (Gronow, 2009).

\section{Meanings}

The WhatsApp group members share understandings of how the practice should be performed. This draws on the notion of "habitus" (Bourdieu, 1984), later redefined by Bourdieu (2000, p. 19) as "a set of dispositions, reflexes and forms of behaviour that people acquire through acting in society". Drawing on their life experiences, people know instinctively how to do things, acting in accordance with the context. There is a tacit assumption, for example, that if a WhatsApp message is posted late in the evening, it is unlikely to receive an immediate response. Similarly, if individuals bombard their peers with messages, they will not be looked upon favourably. This does not mean there will be no disagreements or misunderstanding but these notions of social normality are significant in making sense of practices.

\section{Competences}

Finally, there are certain competences that are essential to be able to perform the practice effectively. Practitioners will draw on their knowledge of the basic constituents of the technological artefact, for example, how to turn on and charge their phone, set up a group chat and post messages, photos and audio files. They will also need to recognise conventions of texting, including abbreviations and emoticons. These competences are, however, not exclusive to the practice of mobile messaging as these functions can be performed using other technologies such as email.

\section{A community of practice framework}

From a social practice perspective, the relationship between individuals is key to the nature of reality. Social phenomena can only be analysed in the "site of the social" (Schatzki, 2002), implying a different "ontological commitment" (Kelly, 2015, p. 152) than psychological views which emphasise the role of the individual in the social world. In practice approaches, "the social is a field of embodied, materially interwoven practices centrally organized around shared practical understandings" (Schatzki, 2001, p. 11). Socially embedded means of communication are thus central to the concept of a "community practice theory", the basic premise being that valuable information and 
knowledge, both explicit and tacit, can be shared more effectively if groups share the same values and aims. Wenger (1998, p. 74) argues that a community of practice is not synonymous with "a group, team or network"; it is defined specifically as "people who share a concern, a set of problems, or a passion about a topic, and who deepen their knowledge and expertise in the area by interacting on an ongoing basis" (Wenger, McDermott, \& Snyder, 2002, p. 9). Although the concept of a community of practice is not new, the theory has gained importance in different fields such as online environments, education and business management since its inception in the early 1990s (Lave \& Wenger, 1991) and has undergone several revisions (Wenger, 1998; Wenger et al., 2002). The word "community" arouses feelings of warmth and trust, and there is a sense of "boundedness" between its members (Trowler, 2008). As the practice becomes normalised, fears of uncertainty and self-doubt are reduced). Its predictability not only helps to build confidence, but it makes the everyday lives of its practitioners easier as there is less effort involved: there is a kind of "ontological security" (Giddens, 1984, p. 23, 50) which comes from the routinisation of the practice. For example, on the teacher development programme, the participants recognise that if they post a message using WhatsApp and receive a double tick, a response is likely.

According to Wenger (1998), practice is what brings coherence to a community. His framework comprises three dimensions: joint enterprise, which refers to the extent to which members are engaged and committed to a common goal; mutual engagement, which clarifies how relationships are built and sustained, and shared repertoire, the resources specific to the community, including signs, symbols, stories and discourse, understood by the group. All three dimensions are essential to the development and maintenance of the practice. Learning is enhanced as individuals' identities are constituted through participation in the community of practice.

With reference to the WhatsApp group, the trainee teachers wanted a space where they could share ideas and information to support them on the higher education programme; there was thus likely to be a certain degree of commitment to the practice. This "joint enterprise" may be interpreted differently by individuals and evolve over time as the practice meshes with other practices (Schatzki, 2005) but, in using WhatsApp, the participants will seek out knowledge which is meaningful to them. They may want reassurance, support with an assignment or to catch up on a session they have missed.

Wenger (1998) concedes that sustained mutual relationships are not always harmonious yet this idea is not referenced fully in his conceptual framework (Jewson, 2013). The terms he proposes suggest a different view. "Joint enterprise" and "community" imply that a community is unified in its belief and practice (Fox, 2002) and rather static (Cox, 2005). This idealised view of a community does not sufficiently account for the power struggles within communities (Fox, 2000;) and its concept suggests that those who do not agree with its goals are disloyal and acting in their own interests (Nicolini, 2012). In addition, in an educational setting, it presumes that the interactions within a community of practice will always be meaningful to everyone and enhance learning. However, this is unlikely to be the case. They may not be sufficiently innovative (Swan, Scarbrough, \& Robertson, 2002), trivial, and, at worst, reinforce misunderstandings and prejudices. 
Despite these reservations about the concept, "community of practice", it was still valuable to observe how a practice was enacted within an electronic network comprising mostly novice teachers who required additional emotional and academic support. Wenger's framework (1998) provided a useful starting point to analyse the extent to which the indicators proposed in relation to a "shared repertoire" within a community of practice were evident in the WhatsApp group or whether there were fundamental disagreements about the practice in question.

\section{Methods and methodology}

Practice theory is particularly applicable to examining social change at the meso level as practices are situated and evolve differently depending on context. One of the key aims of this project was to examine the norms, behaviours and attitudes of the WhatsApp users in a teacher training context, and focus groups were a way of studying how individuals collectively understood the practice. From the knowledge and experiences shared by the practioners, it was possible to generate valid common themes and observe group interactions (Morgan, 1996).

In respect of studying social practices, focus groups and interviews have been criticised as they fail to capture the dynamic nature of their performance (Martens, 2012; Nicolini, 2017), and it is difficult for participants to articulate the intricacies of practices, to explain and make sense of what they do. Ideally, it is beneficial to observe how the practice is enacted in real time(: to see the practice in action. However, it would be time-consuming and difficult to witness the everyday reality of the WhatsApp practice without invading individuals' privacy and causing them to feel self-conscious about their postings. A focus group discussion can also provide some insights into how the technology is interpreted and adopted by the users of a community of practice.

As with much qualitative research, there is an unequal power relationship between the researcher and the participants (Brinkmann \& Kvale, 2005) which raises specific ethical dilemmas. Although with focus groups the researcher can take a back seat in the process to an extent, allowing the participants to pursue their own agendas (Wilkinson, 1998), the researcher will still be in control, organising the focus groups, steering the discussion and interpreting the data. In addition, my dual role as researcher and tutor was an ethical concern. Since I had previously taught the students on the teacher education programme, this may have resulted in the participants being too eager to please, exaggerating events in the hope of assisting me in my study. However, my "insider" status was also a strength. I had a certain "street credibility" (Robson \& McCartan, 2016, p. 399) as I recognised some of the difficulties these students had on the training programme and their reasons for wanting more "virtual" group collaboration. The participants already trusted me: I did not have to build rapport or fake a friendship with them (Duncombe \& Jessop, 2002). They did not feel intimated by my presence and, were happy to discuss the topic.

Trowler (2014) highlights one further difficulty that insider researchers particularly face in their investigations of social phenomena: the ability to distance themselves from the practice and detect its "strangeness" (Garfinkel, 1967). One positive aspect here was that my knowledge of WhatsApp was limited so I could approach the practice with relatively "fresh eyes" (Trowler, 2014, p. 8). 
Three focus groups were conducted: two comprising participants on year one of the teacher training programme and one from year two. All participants were aged between 28 and 50, from a variety of academic and vocational disciplines. The groups were predominately female, reflecting the composition of the teacher training cohort, and consisted of four to six members. The discussions were held at the participants' place of study to provide a familiar setting and recorded using an audio rather than a video source to create a more relaxed, uninhibited environment.

The initial "focusing exercise" (Bloor, Frankland, Thomas, \& Robson, 2001) encouraged the participants to reach a consensus on a list of phrases associated with the perceived benefits and disadvantages of WhatsApp, including "a sympathetic ear", "a way of sharing ideas and resources" and "a nuisance" to expose the group's assumptions of the practice and to ease them into the discussion. Thereafter, the idea was to facilitate the discussion only when necessary, allowing the participants to talk about aspects of the practice which were of significance.

From the focus group data, participants' comments were coded and then conceptualised, firstly in terms of broad themes, namely those that represent a unique advantage of WhatsApp and are likely to persist, and then broken down into sub-categories (Barbour, 2008). In addition, to make sense of the interaction between the participants on the teacher training programme and their insights into the WhatsApp practice, a simple version of conversational analysis was used. By viewing the focus groups as "social enactments" (Halkier, 2010), it was possible to gain a richer analysis of the data, observing to what extent the participants negotiated meaning and had a "shared repertoire" (Wenger, 1998) in relation to their discussion of the practice. Specifically, the following indicators were analysed:

- the ability to assess the appropriateness of actions and products

- specific tools, representations, and other artefacts

- local lore, shared stories, inside jokes, knowing laughter

(Wenger, 1998. p. 125)

In the subsequent analysis of the data, participant interaction has been transcribed as closely as possible to understand group norms and meanings. A simplified code to aid interactional analysis, based on Silverman's, 1993 transcription symbols, is provided in Additional file 1.

\section{Research findings and discussion}

Following Spotswood et al. (2015), the findings from the focus group interactions have been categorised into the three elements of Shove et al.'s (2012) social practice theory to discuss their interrelationship and to analyse any changes in practice of the mobile messaging service over the two-year teacher education programme. Where appropriate, features of the socio-technical interaction between the participants are also highlighted in relation to Wenger's (1998) community of practice framework.

\section{Materials}

Each member of the social network had access to a mobile phone and the internet, both essential to the practice of WhatsApp. One participant was still able to interact with the year one group whilst travelling in Bangladesh, thus highlighting the 
capability of the mobile messaging service to transcend spatial and temporal boundaries.

It was interesting to note why WhatsApp had been chosen over another mobile messaging service. This links to the "meanings" element of the social practice framework, namely the participants' shared understanding of its significance. The groups cited familiarity, cost and convenience as the main reasons for its selection: "it's at your fingertips"; "it's the only one I know" and "there's the advantage of sending pictures and they're free so long as you've got the group broadband". One group associated WhatsApp with the older generation because of its ease of use in comparison with other multimedia mobile applications:

$L^{1}$ : I think it's maybe a generational thing because (.) had we been sixteen it would have been um

PR Instagram no $=$

$\mathrm{DM}=$ Facebook

\section{LE not Facebook}

PR Snapchat

AB Snapchat [something similar

LE [Snapchat or something

AB Snapchat but older age (..) I think they are more into WhatsApp (.) it's =

$\mathrm{LE}=$ it's easier

$\mathrm{AB}$ it's easier

PR definitely easier

On the surface, this discussion suggests that the community can agree on and assess the appropriateness of products as outlined in Wenger's (1998) community of practice framework. Although there is a slight disagreement in the group when LE dismisses the suggestion of Facebook as the primary means of digital communication among the young, the other participants appear to accept the alternative, Snapchat, without argument. The use of repetition is evident in the discourse and this plays a central role in maintaining personal relationships (Tannen, 1987). "Snapchat" is repeated several times, indicating a human desire to participate in the conversation and show interest in the topic. The repetition of "easier" with the addition of the emphatic "definitely" reinforces the group's attitude towards WhatsApp. However, this discussion may also highlight the unequal power relations within the group. The more confident and dominant members of the group such as LE are not afraid to express their opinions whereas quieter individuals may support a view out of a desire for conformity rather than genuine agreement. 
Generally, the extent to which users adopt new technology will depend on their private and professional lives and the limits they wish to place on these domains (Lehtonen, 2003). One participant highlighted the importance of keeping the social and professional aspects of his life separate:

I try to switch off everything from work when I'm in social mode (...) so then I don't like getting reminders about work

He associated the study group with the professional sphere of his life as a teacher and was reluctant to blur these boundaries. Most participants, however, had little reservation about bringing WhatsApp home with them; they did not consider it to impact too heavily on their privacy. Nevertheless, one member's comment that she felt a certain pressure to respond to messages produced murmurs of agreement:

LE I think the only disadvantage with the WhatsApp group it's that(...) I think it may be a slight invasion of privacy

$\mathrm{DM} \mathrm{mm}$

LE because you get all these messages that you have to [look at

DM [yeah

LE and [just in case people think

PR $[\mathrm{mm}$

LE well (..) she's too busy or important to (.) respond sort or and it's only so-and-so answering and [you feel

$\mathrm{DM}[\mathrm{mm}$

LE a little pressure of guilt

Increased rapidity in communication enables the participants to keep in contact but it also encroaches on their daily routines. The frequency of postings will depend on the time individuals have in their everyday schedules and the importance they attach to the practice.

\section{Meanings}

From the discussions, the year one teacher training cohort was clearly more emotionally invested in the WhatsApp group than the trainees on the second year of the course. For the latter group, the mobile messaging service was peripheral to other practices. They appreciated its existence, but its primary aim was not to construct their knowledge. They commented that the WhatsApp group had consistently served two main functions over the two-year programme: as a reminder, for example of assignment 
deadlines, and as a more rapid and efficient means of disseminating information than other forms of communication such as email:

NS if people have missed a class for whatever reason quite often will put some quest (.)

RA if they're running late

[group laughter]

DC yeah that's the main thing (.) I'm not going to be there

[group laughter]

I can't find a parking space

[group laughter]

GN which I think is good because (.) if you have to go through all the emails and stuff like that (.) you know it's more instant (.) to let your tutor know that you're going to be late

It is interesting to observe the effect of laughter in this conversation in respect of Wenger's (1998) views on what lends coherence to a community of practice. Laughter plays an important role in interaction (Jefferson, Sacks, \& Schlegoff, 1987) and, here, the participants demonstrate a shared understanding of its purpose. Over time WhatsApp had been appropriated in a different way than was possibly originally intended and this "knowing laughter" (Wenger, 1998) suggests this is recognised by the group. It also demonstrates a kind of intimacy between the members even if this may not stretch beyond the boundaries of the community of practice.

The participants mentioned that they were members of multiple communities of practice including work, church and family groups. They brought their different experiences and attitudes of networking in other communities to the WhatsApp group but did not necessarily have a close affiliation with their co-members:

The tutors in the hairdressing department they created one in December and I kind of exited that one straightaway because (....) we haven't really got anything in common apart from teaching (....) we don't talk outside the classroom so I thought why am I going to be part of a group chat.

This highlights one potential limitation of applying Wenger's community of practice framework (1998) to the WhatsApp group. Although Wenger recognises that individuals can "participate in multiple communities of practice at once" (ibid, p105), the concept does not sufficiently consider individual differences and their motivations. The term "community" implies both inclusion and exclusion (Jewson, 2013). Individuals will have alternative commitments and, therefore, are unlikely to give one group their undivided attention. If it is not meeting their needs or they feel excluded, this will result in withdrawal from the community. 
For the year one group of trainee teachers, there was a more positive attitude towards the mobile messaging service. One of the primary reasons for using WhatsApp appeared to be strengthening social relationships to gain access to emotional support and resources:

PR I think we are mainly using it for sharing =

$\mathrm{AB}=$ sharing ideas and resources

DM yeah and also passing on information particularly for those who missed the lesson (...) there are times when someone's ill or (.) Jill ${ }^{2}$ graduating or I might send a get well soon and

LE so this is the sympathetic ear

However, although the year one trainees mentioned they had "bonded as a group" and worked "well as a team", there were comments about some members' lack of participation within the community. One practitioner felt dejected after reaching out to support one of her peers on WhatsApp and receiving no response:

She didn't respond at all ... and in the end (..) I even sent her private messages I called her and she still didn't respond

Clearly, not everyone had the same sense of allegiance to the group; they were willing to give their mobile number and join the group chat, but rarely contributed and did not expect anything in return. Because WhatsApp is a 'virtual community', individuals can easily lurk in the background, only dropping in when they see fit. They may not want to leave the group completely in case they miss out on something, but they avoid becoming too heavily involved. They still want to create their own personal space and mobile technology can interfere with this.

One practitioner commented that he intentionally kept a distance from the group to avoid becoming embroiled in "silly things":

DM I like to listen and whatever goes on in the WhatsApp group I'll read

\section{PR I don't ()}

DM and I don't think I need to contribute to that =

$\mathrm{PR}=\mathrm{mm}$

DM because it's nothing to do with me (...) even when miaow was going on

[sounds of laughter]

I just left it alone and it took care of itself

The "miaow" is a reference to an "inside joke" (see Wenger's, 1998 indicators of a shared repertoire in a community of practice), a shared history between the 
participants, relating to an incident as to whom should be appointed course representative. The way the discussion was conducted on WhatsApp caused disagreement and resentment, but the group felt they had learned important lessons from this episode and attributed it to a "settling in period". Community members will monitor each other's behaviour (Harris \& Shelswell, 2005) as they adjust to new norms and familiarise themselves with the technological artefact. This also, however, highlights the social dynamics at play within groups. Some individuals will feel the need to adopt the role of "controller" or "enforcer" of appropriate message content for the good of the community, but this may cause practitioners to feel restricted in their postings. They may appear to accept these power inequalities but inwardly feel resentful and withdraw from participation in the group. In this case, although the incident was resolved, it had clearly not been forgotten and unquestionably led to tensions. The interactions within a community will not always be indicative of participants' true feelings: "communities are defined by as much by whom and what they exclude as by what they contain" (Harris \& Shelswell, 2005, p. 168).

Both the year one and two teacher training groups agreed they were comfortable exchanging resources and ideas for the good of everyone rather than for individual gain. Generally, they did not expect tangible returns, for example a copy of an assignment, but benefited from peer collaboration, as highlighted here:

DC I think information should be shared

RA yeah

DC so (.) if you've done something and (..) someone's struggling well (.) have you tried this have you tried that (.) would you like me to have a look at it

However, several practitioners on year two of the programme agreed that WhatsApp was not the best forum for more "serious" topics, implying that mobile interactions are not necessarily meaningful for educational purposes:

GN talking about theories and have arguments over it or discussions in class (.) that would help me (..) to actually get (..) more (.)

TC but not on WhatsApp

GN no

DC it's too fiddly to do on WhatsApp

This links to the "materials" element of Shove et al.s (2012) social practice theory. The small size of mobile phones exemplifies portability and convenience but also proves to be a challenge for learning (Kress \& Pachler, 2007). Other digital technologies such as laptops and iPads are better equipped to dealing with large amounts of data and the group recognised that there were limitations to using WhatsApp to discuss aspects related to pedagogy. 
Several participants highlighted the importance of reciprocity in maintaining social relationships (Blau, 1964;). There was an expectation that their co-members would feel a sense of moral obligation to willingly share knowledge and information on a continual basis. They also expressed some irritation with the more passive members of the group whom they felt were not "pulling their weight":

LE some people on the group they're just not responding =

$\mathrm{DM}=$ yeah

LE I think that's not good behaviour =

$\mathrm{AB}=$ yeah $\mathrm{I}$ tried to challenge Michael on that

LE yeah

$\mathrm{AB}$ you are a part of the group so you should just chip in something

However, one focus group agreed that this "altruistic reciprocity" (Diekman, 2004) depended on what was at stake:

MA I don't think there is much to benefit from holding onto anything and the beauty of this course is that you pass by a pass

$\mathrm{HN} \mathrm{mm}$

MA it's not like by a percentile (..) that the top two are going to pass or get a distinction or something (..) everybody gets a pass

FACILITATOR so do you think it would be different if there was a grade

MA absolutely

WG it would be different

MA there isn't one and I feel that when I was doing my deGREE (...) I was holding on (.) I was very competitive

WG uh huh

MA and I wanted to get the top mark and I did [laughs] but that's because I wanted to push myself (...) but I wouldn't show my assignment (.) I would show the resources that I'd be using but I wouldn't say like here's my (..) essay

From these discussions, it was clear that reciprocity and social capital are interlinked but participants might refrain from sharing information if it affects their personal interests such as an assessment outcome. This idea is not typically associated with the notion of a 
community where reciprocal social relations are central to forging relationships and building trust (Putnam, 2000). In the WhatsApp group, individuals made a choice whether to collaborate: they balanced the concepts of equity, the degree of participation by all members; reciprocity; and competition (Bolton \& Ockenfels, 2000), comparing their performance with others. This view suggests that identity formation is more fluid and complex than proposed in Wenger's community of practice framework (1998, p. 11): the notion of an "inseparable duality" between the individual and the situated learning experience. Power relations, the rituals of the practice and external structures play a significant role in the management of knowledge through social interactions (Contu \& Willmott, 2003). The trainee teachers' interactions on the WhatsApp group were shaped by their own motivation, ambitions and external constraints of time, space and circumstances (). The group only met once a week on the teacher education course and access to institutional resources was problematic. The extent to which the practitioners learned from each other can, thus, not be analysed in isolation from the social structures and power relations inherent in the local context.

\section{Competences}

All the practitioners were proficient in the basic functions of WhatsApp and how to.

participate in group chats. They made use of their existing knowledge of texting and their experience of interacting on other mobile messaging groups. However, for the year one WhatsApp group, there was initially some confusion over how to display names rather than just their phone numbers. Some people may have wanted to preserve their anonymity but given this is a social network comprised of individuals who know each other and have face-to-face contact at least once a week when they attend their course, this seemed unlikely. It was more probable that they didn't possess the "know-how" (Shove et al., 2012) to adjust the settings on their mobile phones. Some felt that this skill was essential to the effective performance of the practice, which links again to the "meanings" aspect of Shove et al.'s (ibid) social practice theory, particularly at the beginning of the course to build social relations:

$\mathrm{LE}$ at the beginning that was the biggest problem not knowing who's who

PR and what do you teach and where do you teach [and what's your specialism

LE [and people just have their numbers and there was no profile picture (.) and I'm thinking at the beginning I need to know who I'm speaking to

Here, LE associates the practice of WhatsApp with strengthening social ties but to engage in any meaningful discussions, she needs to feel secure. If practitioners do not divulge their identities, there is a barrier between them and the rest of the group. They are not conforming to the norms of the community and full participation, often seen as a prerequisite for building trust and group solidarity, will not be possible.

During the two-year higher education programme, the mobile messaging service was used to express a range of emotions (see Additional file 2 for some typical postings by both groups). The practitioners agreed that messages should be connected to matters concerning the course, only using WhatsApp occasionally to "share snippets of each 
other's lives". One participant commented that she felt supported by the group after suffering a bereavement, but others felt there was a tendency for individuals to reveal too much about their ailments. This point arose several times in the discussions and was clearly a source of amusement:

LE some of the things are just so irrelevant like last week there was a little too much information about um I'll be going to the toilet

PR yes

$\mathrm{AB}$ every second [laughs]

PR just a general I'm [ill

\section{LE [I'm ill}

\section{PR I won't be in}

This emphasises the view that communities of practice do not always fulfil their original aim, in this case to consistently share meaningful information and knowledge. The content of the WhatsApp interactions was frequently perceived by its members as mundane, thus contradicting the idealised view of communities of practice as highly functional and collaborative learning spaces (Lea, 2005).

Finally, the practitioners also used non-verbal means of communication such as images and emoticons to negotiate meaning and maintain social relationships. These symbols are "specific representations" (Wenger, 1998), recognised by the communities of practice, to compensate for the lack of face-to-face contact. An example of a text message where graphic displays are used is shown below:

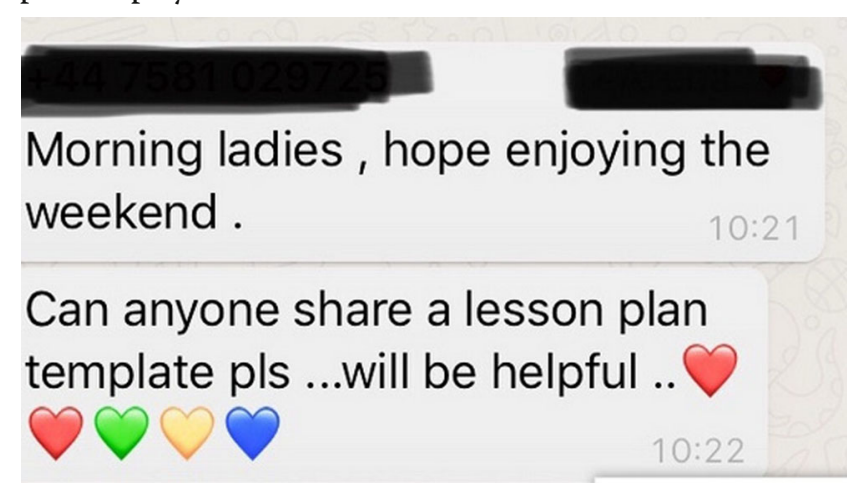

The hearts accompany a user's request for a lesson plan. They act as a "softener" (Skovholt, GrØnning, \& Kankaanranta, 2014), a more tentative way of asking for something. This conveys the idea the sender of the message does not wish to be a burden, and the image, the abbreviated form of please: "pls", and the reason given for the request: "will be helpful", are all instrumental in emphasising the sender's positive intentions. This highlights the role of language and literacy practices in understanding how social relationships are sustained within a community of practice (Barton \& Hamilton, 2005). Participation in the WhatsApp group relied on making sense of these "semiotic 
markers" (ibid) in addition to understanding the history of interactions and power relationships within the community.

Interestingly, the aforementioned WhatsApp message is addressed to the "ladies" of the community even though there are three male members in both the year one and two groups. By their own admission, the men tended to adopt a more passive role in the WhatsApp groups. There was a suggestion that at times they felt marginalised or felt the WhatsApp postings had little or no relevance to them as indicated here: "it's nothing to do with me"; "I don't interact as much as the ladies ... ..there are only two men in the group" and "I'm the ghost". Although this was beyond the scope of the research project, it would be interesting to note whether these gender patterns of interaction were also present in the face-to-face sessions on the programme.

\section{The relationship between WhatsApp and other communicative practices}

In this local context, innovations in mobile technology signified a change in other communicative practices. Email was still used by the tutors to maintain social ties and send reminders and notices to the group. However, it was rarely used by the practitioners: the mobile messaging service had replaced email as the primary mode of communication outside the classroom: WhatsApp was viewed as a more instant, informal and convenient means of self-expression. The trainee teachers also had the benefit of face-to-face contact in their weekly sessions on the teacher education programme which provided an opportunity to clarify any misunderstandings that had arisen from the WhatsApp group interactions. It enabled them to build on their personal relationships away from their mobile phones; this, in turn, incentivised them to continue interacting via WhatsApp. Face-to-face communication was thus essential in maintaining personal relationships outside the "virtual community" (Kimble, Hildreth, \& Weight, 2000).

In addition, the strength of the relationship between individuals and the nature of communication had a significant impact on the practice used by the trainee teachers. There were instances when it was deemed appropriate to contact individuals in the group privately via SMS (short message service) or by a phone call because the practitioners wanted to share information relating specifically to their teaching discipline which they felt was not relevant to the whole group. This raises the question as to whether the WhatsApp community necessarily evoked feelings of unity. From their list of contacts, users could select the individual who best met their personal needs, ignoring the rest of the group, to increase "social efficiency" (Kopomaa, 2002). The desire to be part of a group, therefore, functioned alongside an individualistic need for control.

Overall, on the teacher training programme, WhatsApp complemented other forms of social interaction rather than replaced them. The practitioners balanced the advantages of using it with other communicative practices and deemed it a practice worth pursuing. Its use did not change significantly over the course of the programme but was modified as individuals became more confident with the course requirements and protocols and craved more independence. As highlighted by Shove et al. (2012), if a practice is perceived to be "internally rewarding", it is more likely to persist, and this appeared to be the case here.

\section{Conclusion}

Agar and MacDonald (1995) cite a key reason for using focus groups in qualitative research is their ability to reveal information unbeknownst to the researcher. The extent 
to which the year one teacher training cohort had adopted WhatsApp on their course was a revelation to me, their former tutor. The year two WhatsApp group was a more loosely-coupled community. Its participants did not rely overly on the mobile messaging practice for emotional and social support during the programme, but it was still a welcome resource.

Analysing WhatsApp from a social practice perspective facilitated a greater understanding of the practitioners' commitment to the mobile messaging service, its co-existence with other practices and its development over the two-year higher education teacher training programme. In addition, exploring the socio-technical interactions in the electronic network revealed some interesting insights. It was possible to recognise some of the indicators for a "shared repertoire" as outlined in Wenger's (1998) community of practice framework. Trainee teachers, particularly if new to an organisation, can feel isolated and may not receive the mentoring support they need or desire. The WhatsApp group provided the emotional crutch craved by many of its participants and, generally, positively shaped the experiences of the novice practitioners on their education programme. What was less evident was the extent to which they learned from each other.

Community of practice theory is a useful way of considering how learning occurs beyond the individual. However, it is a slippery concept, and as evidenced in this research project, does not fully address issues of power and conflict, gender divides and the importance of language in negotiating meaning. There is likely to be discord and dysfunctionality within communities of practice however selfless and harmonious they may superficially appear. In this research context, the trainee teachers manoeuvred between multiple communities of practice to draw on additional resources rather than being reliant on one social network only.

As highlighted previously, one limitation of this research is its reliance on participant discussion rather than observing the practice in action. Consequently, like Spotswood et al. (2015) findings, "the meanings" element of Shove et al.'s (2012) social practice theory yielded the richest data. Nevertheless, this small-scale research revealed how WhatsApp is being integrated into informal educational communities of practice and further studies would benefit from focusing on the additional benefits it could bring to educators' professional development and the impact it has on social interaction. Not all technology endures but for the time being, at least, it seems that WhatsApp is here to stay. We should look beyond viewing it as a fad, a chatting tool among the young, to exploring how its practice in social networks canbe used to build and maintain social relationships and provide invaluable emotional support in educational settings. .

\section{Endnotes}

${ }^{1}$ Participants have been provided throughout with alternative initials to maintain confidentiality

${ }^{2}$ change of names throughout to protect anonymity

\section{Additional files}

Additional file 1: Transcription Symbols. (DOCX $13 \mathrm{~kb})$ 
Additional file 2: Some typical messages posted by the trainee teachers on the higher education programme. (DOCX $408 \mathrm{~kb})$

\section{Acknowledgements}

I would like to acknowledge the support of academic staff on the Doctoral Programme in Higher Education Research, Evaluation and Enhancement at Lancaster University from which this publication has arisen.

Funding

I received no funding as part of this research.

\section{Availability of data and materials}

The datasets used and analysed during the current study are available from the corresponding author on reasonable request.

\section{Author's contributions}

I am the sole author. The author read and approved the final manuscript.

\section{Competing interests}

The author declares that she has no competing interests.

\section{Publisher's Note}

Springer Nature remains neutral with regard to jurisdictional claims in published maps and institutional affiliations.

Received: 15 June 2018 Accepted: 25 March 2019

Published online: 26 April 2019

\section{References}

Adami, E., \& Kress, G. (2010). A social semiotic analysis of mobile devices: Interactions of technology and social habitus. In N. Pachler, B. Bachmair, \& J. Cook (Eds.), Mobile learning: Structures, agencies, practices. London: Springer.

Agar, M., \& MacDonald, J. (1995). Focus groups and ethnography. Human Organization, 54(1), 78-86.

Barbour, R. (2008). Doing focus groups. London: Sage.

Barton, D., \& Hamilton, M. (2005). Literacy, reification and the dynamics of social interaction. In D. Barton, \& K. Tusting (Eds.) Beyond communities of practice: Language, power and social context. Cambridge: Cambridge University Press.

Blau, P. M. (1964). Exchange and power in social life. New York: Wiley.

Bloor, M., Frankland, J., Thomas, M., \& Robson, K. (2001). Focus groups in social research. London: Sage.

Blue, S., Shove, E., Caromona, C., \& Kelly, M. P. (2016). Theories of practice and public health: Understanding (un) healthy practices. Clinical Public Health, 26(1), 36-50.

Boden, D., \& Molotch, H. (1994). The compulsion to proximity. In R. Friedland, \& D. Boden (Eds.), Nowhere: Space, time and modernity. Berkeley: University of California Press.

Bolton, G. E., \& Ockenfels, A. (2000). ERC: A theory of equity, reciprocity, and competition. American Economic Review, 90, 166193.

Bourdieu, P. (1984). Distinction. London: Routledge.

Bourdieu, P. (2000). The politics of protest. An interview with Kevin Ovenden. Socialist Review, \#42.

Brinkmann, S., \& Kvale, S. (2005). Confronting the ethics of qualitative research. Journal of Constructivist Psychology, 18(2), $157-$ 181.

Cheng, S., Olsen, W., Southerton, D., \& Warde, A. (2007). The changing practice of eating: Evidence from UK time diaries, 1975 and 2000. The British Journal of Sociology, 58(1), 39-62.

Churchill, D., \& Hedberg, J. (2008). Learning object design considerations for small-screen handheld devices. Computers and Education, 50, 881-893.

Contu, A., \& Willmott, H. (2003). Re-embedding situatedness: The importance of power relations in learning theory. Organisation Science, 14(3), 283-297.

Corradi, G., Gheradi, S., \& Verzelloni, L. (2010). Through the practice lens: Where is the bandwagon of practice-based studies heading? Management Learning, 41(3), 265-283.

Cox, A. (2005). What are communities of practice? A comparative review of four seminal works. Journal of Information Science, 31(6), 527-540.

Darnton, A., \& Evans, D. (2013). Influencing behaviours: A technical guide to the ISM tool. Edinburgh: The Scottish Government https://www2.gov.scot/Resource/0042/00423531.pdf.

Diekman, A. (2004). The power of reciprocity: Fairness, reciprocity and stakes in variants of the dictator game. Journal of Conflict Resolution, 48(4), 487-505.

Duncombe, J., \& Jessop, J. (2002). "Doing rapport" and the ethics of "faking friendship.". In M. Mauthner, M. Birch, J. Jessop, \& T. Miller (Eds.), Ethics in qualitative research. London: Sage.

Ellison, N. B., \& Boyd, D. (2013). Sociality through social network sites. In W. H. Dutton (Ed.), The Oxford handbook of internet studies, (pp. 151-172). Oxford: Oxford University Press.

Evans, D., McMeekin, A., Warde, A., \& Southerton, D. (2012). Sustainable consumption, behaviour change policies and theories of practice. In The Habits of Consumption: COLLEGIUM: Studies across disciplines in the humanities and social science, (vol. 12, pp. 113-129). Open Access Book Series of the Helsinki Collegium of Advanced Studies: Helsinki.

Fox, S. (2000). Communities of practice, Foucault and actor-network theory. Journal of Management Studies, 37(6), 853-867.

Fox, S. (2002). Networks and communities: an Actor-Network critique of ideas on community and implications for networked learning. In Networked Learning. 
Garfinkel, H. (1967). Studies in ethnomethodology. Englewood Cliffs: Prentice Hill.

Giddens, A. (1984). The constitution of society. Cambridge: Polity Press.

Gram-Hanssen, K. (2009). Standby consumption in households analysed with a practice theory approach. Journal of Industrial Ecology, 14(1), 150-165.

Gronow, J. (2009). Fads, fashions and "real" innovations: Novelties and social change. In E. Shove, F. Trentmann, \& R. Wilks (Eds.), Time, consumption and everyday life, (pp. 129-143). Oxford: Berg.

Halkier, B. (2010). Focus groups as social enactments: Integrating interaction and content in the analysis of focus group data. Qualitative Research, 10(1), 71-89.

Halkier, B., \& Jensen, J. (2011). Methodological challenges in using practice theory in consumption research: Example from a study on handing nutritional contestations of food consumption. Journal of Consumer Culture, 11(1), $101-123$.

Hargreaves, T. (2011). Practice-ing behaviour change: Applying social practice theory to pro-environmental behaviour change. Journal of Consumer Culture, 11(1), 79-99.

Harries, T., \& Rettie, R. (2017). Walking as a social practice: Dispersed walking and the organisation of everyday practices. Sociology of Heath and IIIness, 38(6), 874-883.

Harris, S. R., \& Shelswell, N. (2005). Moving beyond communities of practice in adult basic education. In D. Barton, \& K. Tusting (Eds.), Beyond communities of practice: Language, power and social context. Cambridge: Cambridge University Press.

Independent (2016). Retrieved on $18^{\text {th }}$ January, 2018. http://www.independent.co.uk/life-style/gadgets-and-tech/news/ whatsapp-to-go-completely-free-and-drop-annual-subscription-price-a6818971.html

Jefferson, G., Sacks, H., \& Schlegoff, E. A. (1987). Notes on laughter in pursuit of intimacy. In G. Button, \& J. R. E. Lee (Eds.), Talk and social organization. Clevedon: Multilingual Matters.

Jewson, N. (2013). Cultivating networking analysis. Rethinking the concept of "community" within "communities of practice". In J. Hughes, N. Jewson, \& L. Unwin (Eds.), Communities of Practice: Critical Perspectives. London: New York: Routledge.

Katz, J. E., \& Aakhus, M. (2002). Perpetual contact: Mobile communication, private talk, public performance. New York: Cambridge University Press.

Kelly, M. P. (2015). On epistemological and ontological incommensurability in modelling behaviour change. In S. Christmas, S. Mitchie, \& R. West (Eds.), Thinking about behaviour change: An interdisciplinary dialogue. Surrey: Silverback Publishing

Kimble, C., Hildreth, P., \& Weight, P. (2000). Communities of practice: Going virtual. In Y. Malhotra (Ed.), Knowledge management and business model innovation. Hershey, London: Idea Group.

Kopomaa, T. (2002). Mobile phones, place-centred communication and neo-community. Planning Theory and Practice, 3(2), 241-245.

Kress, G., \& Pachler, N. (2007). Thinking about the " $\mathrm{m}$ " in m-learning. In N. Pachler (Ed.), Learning towards a research agency, WLE Centre Occasional Papers in Work-based Learning 1 (pp. 7-32). London: Institute of Education.

Lave, J., \& Wenger, E. (1991). Situated learning: Legitimate peripheral participation. Cambridge: Cambridge University Press.

Lea, M. R. (2005). Communities of practice in higher education. Useful heuristic or educational model? In D. Barton, \& K. Tusting (Eds.), Beyond communities of practice: Language, power and social context. Cambridge: Cambridge University Press.

Lehtonen, T. (2003). The domestication of new technologies as a set of trials. Journal of Consumer Culture, 3(3), 363-385.

Lin, N. (2001). Social Capital. Cambridge: Cambridge University Press.

Maller, C. J. (2015). Understanding health through social practices: Performances and materiality in everyday life. Sociology of Health and IIIness, 37(1), 52-66.

Martens, L. (2012). Practice "in talk" and talk "as practice": Dish washing and the reach of language. Sociological Research Online, 17(3), 22

Merchant, G. (2012). Mobile practices in everyday life: Popular digital technologies and schooling visited. British Journal of Educational Technology, 43(5), 770-782.

Miller, G. (2012). The smartphone psychology manifesto. Perspectives and Psychological Science, 7(3), 221-237.

Morgan, D. (1996). Focus groups. Annual Review of Sociology, 22, 129-152.

Nicolini, D. (2012). Practice theory, work and organization. Oxford: Oxford University Press.

Nicolini, D. (2017). Practice theory as a package of theory, method and vocabulary: Affordances and limitations. In M. Jonas, B. Littig, \& A. Wroblewski (Eds.), Methodological reflections on practice oriented theories. Cham: Springer International Publishing.

Orr, G. (2010). A review of literature in Mobile learning: Affordances and constraints. In Proceedings of 6th IEEE International Conference on Wireless, Mobile and Ubiquitous Technologies in Education (WMUTE), (pp. 107-111). Edinburgh: IEEE.

Putnam, R. D. (2000). Bowling alone: The collapse and revival of American community. New York: Simon and Schuster

Reckwitz, A. (2002a). Towards a theory of social practices: A development in culturalist theorising. European Journal of Social Theory, 5(2), 243-263.

Reckwitz, A. (2002b). The status of the "material" in theories of culture. From 'social structure' to 'artefact'. Journal for the Theory of Social Behaviour, 32, 195-217.

Robson, C., \& McCartan, K. (2016). Real World Research, (4th ed., ). Chichester: Wiley and Sons Ltd.

Schatzki, T. R. (1996). Social practices: A Wittgensteinian approach to human activity and the social. New York: Cambridge University Press.

Schatzki, T. R. (2001). Introduction: Practice theory. In T. R. Schatzki, K. Knorr-Cetina, \& E. V. Savigny (Eds.), The practice turn in Contemporary Theory. London: Routledge.

Schatzki, T. R. (2002). The site of the social: A philosophical exploration of the constitution of social life and change. University Park: Pennsylvania State University Press.

Schatzki, T. R. (2005). The site of organizations. Organization Studies, 26, 465-484.

Shove, E., Pantzar, M., \& Watson, M. (2012). The dynamics of social practice: Everyday life and how it changes. London: Sage Publications. 
Silverman, D. (1993). Interpreting qualitative data: Methods of Analysing, talk, text and interaction. London: Sage.

Skovholt, K., GrØnning, A., \& Kankaanranta, A. (2014). The communicative functions of emoticons in workplace emails: Journal of Computer-Mediated Communication, 19, 780-797.

Spotswood, F., Chatterton, T., Tapp, A., \& Williams, D. (2015). Analysing cycling as a social practice: An empirical grounding for behavioural change. Transportation Research Part F, 29, 22-33.

Swan, J., Scarbrough, H., \& Robertson, M. (2002). The construction of "communities of practice" in the management of innovation. Management Learning, 33(4), 477-496.

Tannen, D. (1987). Repetition in conversation as spontaneous formulaicity. Text and Talk, 7(3), 215-243.

Trowler, P. (2008). Cultures and change in higher education. Basingstoke: Palgrave Macmillan.

Trowler, P. (2014). Practice-focused ethnographies of higher education: Method/ological corollaries of a social practice perspective. European Journal of Higher Education, 4, 1-15.

Urry, J. (2002). Mobility and proximity. Sociology, 36, 255-274.

Warde, A. (2005). Consumption and theories of practice. Journal of Consumer Culture, 5(2), 131-153.

Watson, M. (2012). How theories of practice can inform transition to a decarbonised transport system. Journal of Transport Geography, 24, 488-496.

Wellman, B. (2001). Physical place and cyberplace: The rise of personalized networking. International Journal of Urban and Regional Research., 25(2), 227-252.

Wenger, E. (1998). Communities of practice: Learning, meaning and identity. Cambridge: Cambridge University Press.

Wenger, E., McDermott, R. A., \& Snyder, W. (2002). Cultivating communities of practice: A guide to managing knowledge. Boston: Harvard Business Review Press.

WhatsApp (2018). About WhatsApp. Retrieved January 4, 2018 from https://www.whatsapp.com/about

Wilkinson, S. (1998). Focus groups in Health Research: Exploring the meanings of health and illness. Journal of Health Psychology, 3(3), 329-348.

Will, C. M., \& Weiner, K. (2014). Sustained multiplicity in everyday cholesterol reduction: Repertoires and practices in talking about healthy living. Sociology of Health and IIIness, 36(2), 132-144.

Submit your manuscript to a SpringerOpen ${ }^{\circ}$ journal and benefit from:

- Convenient online submission

- Rigorous peer review

- Open access: articles freely available online

High visibility within the field

- Retaining the copyright to your article

Submit your next manuscript at $\boldsymbol{\nabla}$ springeropen.com 